\title{
Análisis territorial de la problemática ambiental urbana: el caso del municipio de Facatativá, Cundinamarca, Colombia (1980- 2010) $)^{1}$
}

\section{TERRITORIAL ANALYSIS OF URBAN ENVIRONMENTAL PROBLEMS: THE CASE OF THE MUNICIPALITY OF FACATATIVA, CUNDINAMARCA, COLOMBIA (1980-2010)}

ANÁLISE TERRITORIAL DE PROBLEMAS AMBIENTAIS URBANOS: O CASO DO MUNICÍPIO DE FACATATIVA, CUNDINAMARCA, COLÔMBIA (1980-2010)

Para citar este artículo: Hernández Garzón, M. (2019). Análisis territorial de la problemática ambiental urbana: el caso del municipio de Facatativá,Cundinamarca, Colombia (1980-2010). Perspectiva Geográfica, 24(1), 92-115. https://doi.org/10.19053/01233769.9074
Recepción:

17 de agosto de 2017

Evaluación:

14 de febrero de 2018

Aprobación:

15 de marzo de 2019

\section{Resumen}

La situación ambiental actual del área urbana del municipio de Facatativá es la respuesta a los acontecimientos históricos que se han venido presentando frente a procesos de territorialización, expresados en los fenómenos de urbanización e industrialización. Con el fin de comprender los problemas ambientales en el área urbana de este municipio a partir de su análisis territorial, se determinó desde un enfoque

$1 \quad$ Este artículo presenta los principales resultados del proyecto de investigación y tesis de Maestría en Geografía denominado Análisis Territorial de la Transformación y la Degradación Geográfico-Ambiental en el Municipio de Facatativá, 1980-2010

2 Bióloga, Magíster en Geografía del programa de Estudios de Posgrado en Geografía, convenio UPTC - IGAC. Jefe de proyecto, Subdirección de Desarrollo Local y Cambio Global, Fundación Natura.jomic2@gmail.com, mhernandez@natura.org.co 
geohistórico, geopolítico y ambiental la configuración territorial urbana entre 1980 y 2010. Se observó que en Facatativá se han venido presentando complejos problemas ambientales que repercuten en el reconocimiento del valor del medioambiente y los recursos naturales, en la calidad de vida y en la sostenibilidad ambiental. En este sentido, la gestión ambiental territorial se convierte en la estrategia que brinda las pautas para la planificación del territorio, propiciando la igualdad, la equidad y su desarrollo sostenible.

Palabras clave: Facatativá, gestión ambiental, geohistoria, geopolítica, territorio.

\section{Abstract}

The current environmental situation in the urban area of Facatativa responds to the historical events that have taken place regarding territorialization processes, evidenced by urbanization and industrialization. In order to understand the environmental problems in the urban area of this municipality from its territorial analysis, the urban territorial configuration between 1980-2010 is determined from a geohistorical, geopolitical and environmental approach. It is observed that the complex environmental problems of Facatativa impact the recognition of the value of natural resources and the environment, the quality of life and environmental sustainability. Thus, territorial environmental management becomes a strategy to provide guidelines for territorial planning, promoting equality, equity and sustainable development.

Keywords: Facatativa, environmental management, geohistory, geopolitics, territory.

\section{Resumo}

A atual situação ambiental da área urbana do municipio de Facatativá é a resposta aos eventos históricos apresentados diante dos processos de territorialização, expressos nos fenômenos de urbanização e industrialização. Para compreender os problemas ambientais na área urbana deste município a partir de sua análise territorial, determinou-se, a partir de uma abordagem geo-histórica, geopolítica e ambiental, a configuração territorial urbana entre 1980 e 2010. Observou-se que em Facatativá foram apresentados problemas ambientais complexos com impacto no 
reconhecimento do valor do meio ambiente e dos recursos naturais, na qualidade de vida e na sustentabilidade ambiental. Nesse sentido, a gestão ambiental territorial torna-se a estratégia que fornece diretrizes para o planejamento territorial, promovendo a igualdade, a equidade e seu desenvolvimento sustentável.

Palavras chave: Facatativa, gestão ambiental, geohistória, geopolítica, território

\section{Introducción}

Históricamente, la sabana de Bogotá ha estado íntimamente ligada a las dinámicas territoriales del Distrito Capital de Bogotá. Desde la Colonia y durante casi todo el siglo XX, la sabana desarrolló una formación socioespacial particular, cuyos atributos se fueron debilitando en la medida en que Bogotá fue creciendo y se evidenciaron procesos de urbanización y metropolización hacia la segunda mitad del siglo XX.

La forma como han actuado las diversas fuerzas económicas, sociales, políticas e ideológicas, tanto nacionales como internacionales, en el marco de la consolidación y la ampliación del desarrollo capitalista en el país, han incidido en esta nueva conformación espacial que ha traído consigo una serie de complejas formas de territorialización, expresadas en la urbanización y la industrialización de la sabana, que son determinantes en los cambios en el estilo de vida, los imaginarios y las prácticas culturales, las estructuras productivas y el medioambiente de la región.

El municipio de Facatativá, ubicado en el sector centro-occidental del departamento de Cundinamarca, en la provincia Sabana Occidente (Figura 1), ha sido uno de los escenarios en los que se han manifestado estos cambios en la conformación del territorio. La importancia histórica que ha tenido el municipio como centro subregional del departamento lo han hecho atractivo para el desarrollo de diferentes actividades económicas como la floricultura, la industria, la prestación de bienes y servicios y, en los últimos años, para la especulación inmobiliaria, hechos que han incidido en un alto crecimiento demográfico, mayor demanda de servicios básicos y presión sobre sus recursos naturales y el uso del suelo. 


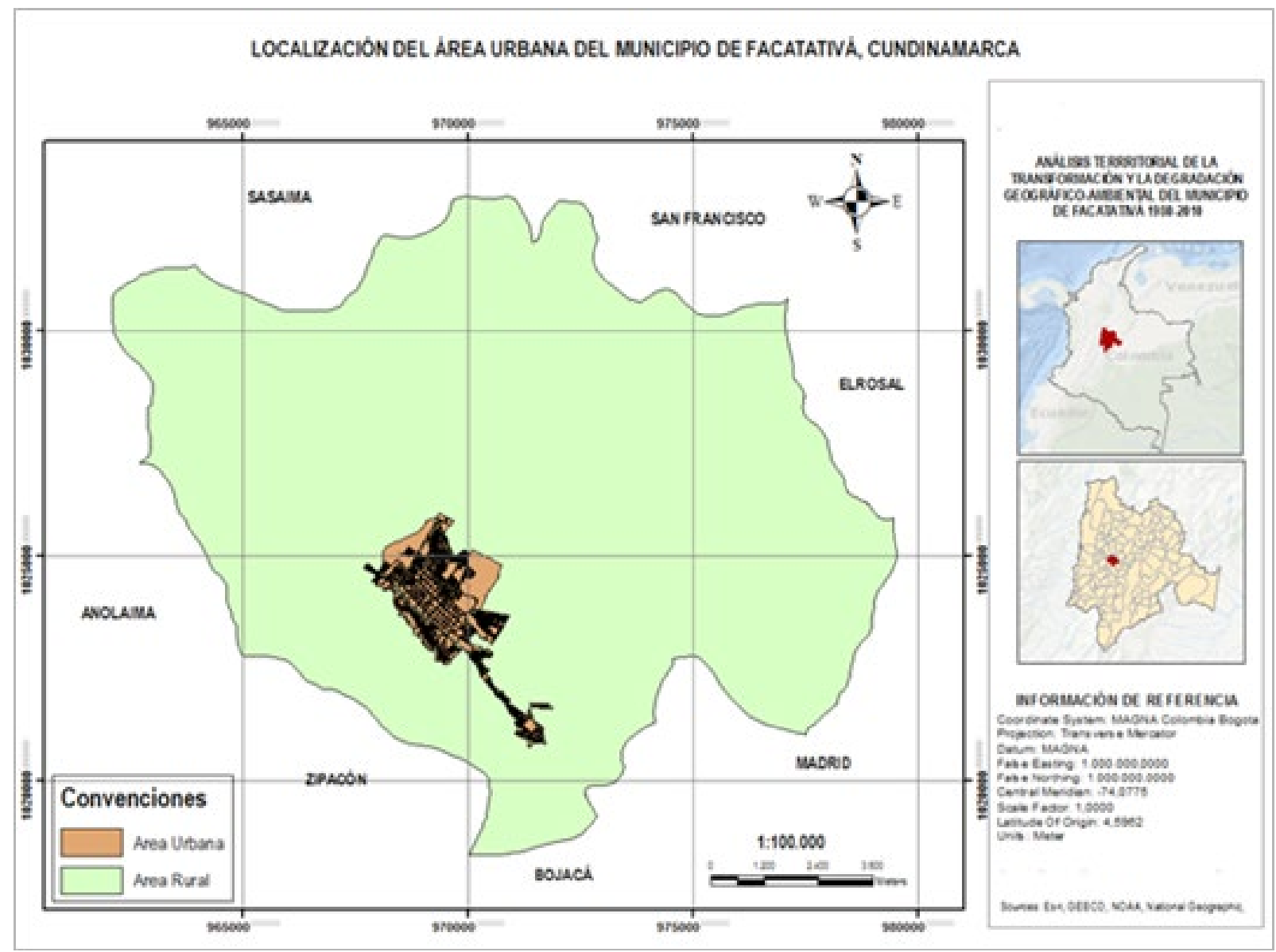

A pesar de que Facatativá es un municipio que presenta importantes potencialidades ambientales y recursos naturales, es evidente el deterioro ambiental y natural al que se ha visto sometido entre 1980 y 2010, lo que pone en evidencia la baja capacidad administrativa del gobierno local y la insuficiente concertación entre las entidades regionales en el propósito de lograr una gestión territorial sostenible, que permita hacer frente a estos problemas que se han generalizado en toda la sabana y cuyas particularidades se han expresado de manera distinta a nivel local.

\section{FIGURA 1.}

Localización del área de estudio, municipio de Facatativá Fuente: Elaboración propia.
El objeto de la investigación fue comprender el proceso de transformación y degradación geográfico-ambiental en el área urbana del municipio de Facatativá a partir de su análisis territorial durante el periodo comprendido entre 1980-2010, periodo en el que comenzó el proceso de urbanización en serie en el municipio, se presentó un mayor crecimiento demográfico y se hizo más visible la expresión de conflictos sociales y territoriales, tanto por las dinámicas locales como por la influencia de las dinámicas regionales con la sabana de Bogotá. Estos hechos han sido determinantes en la configu- 
ración actual del territorio e influyen directamente en el surgimiento de la problemática ambiental urbana.

El enfoque conceptual que sustenta la comprensión de los problemas ambientales urbanos exige una visión holística del territorio que hace indispensable la integración de la geohistoria, la geopolítica y la dimensión ambiental. Así, tenemos que el territorio, como producto social, es el resultado de la acumulación histórica de la producción, la incorporación, la integración y la apropiación social de las estructuras y las relaciones de los diferentes grupos humanos que interactúan en el espacio geográfico (Montañez y Delgado, 1998).

El análisis del territorio es indispensable para comprender la formación socioespacial de un lugar determinado, considerando tanto el componente social como el físico-natural. En este sentido, al análisis del medio natural se incorporan elementos conceptuales procedentes de las ciencias sociales que ayudan a reconocer y comprender las fuerzas condicionantes sociales, culturales, económicas, políticas e institucionales que se han venido articulando históricamente para producir la configuración territorial actual de un lugar y los correspondientes cambios en su medioambiente.

La producción del territorio debe pensarse frente a la relación entre espacio y tiempo, es decir, desde el punto de vista de la movilidad y el cambio permanente, de manera que para examinar el problema de la construcción del territorio y la territorialidad es necesario hacerlo en una perspectiva histórica. Desde este punto de vista, la geohistoria determina el espacio concebido y creado por los hombres organizados en sociedad, ceñidos a condiciones históricas dadas o determinadas. Representa la relación entre la geografía y la historia, una modalidad de interdisciplinariedad obligante en el estudio del territorio y su dinámica (Tovar, 1986, citado por Aponte, 2006), que permite analizar la organización de los territorios en el trascurso de la historia y enfatizar en los momentos en que se revela una mayor vulnerabilidad en la sociedad debido a carencias internas a nivel político, social, económico y ambiental que favorecen las transformaciones de la realidad y de su ambiente (Musset, 2009).

La apropiación y la readecuación del territorio por parte de diferentes agentes sociales generan procesos de transformación espacial con el objetivo de influir sobre la producción del espacio para forjar estrategias de inversión y producción y políticas de carácter económico, jurídico y cultural, procesos que, a su vez, influyen y modifican los procesos geográficos. Por ende, es importante considerar el análisis geopolítico del territorio, analizándolo desde su concreción espacial y temporal frente a la existencia de procesos político-territoriales que pueden elucidar, al mismo tiempo, la forma como se maneja y se transforma el ambiente (López Trigal y Del Pozo, 1999).

El análisis de los problemas ambientales desde el punto de vista geopolítico permite conocer los fenómenos de índole económica, social, política y cultural que se producen y a la vez se reproducen el territorio, con el fin de determinar las posibles interrelaciones entre estos y sus efectos. El abordaje de los problemas ambientales debe considerar las fuerzas de poder que influyen en la dinámica de los elementos que lo conforman, la forma en que determinados grupos utilizan los recursos naturales básicos, los transforman, los alteran y generan, en el peor de los casos, la degradación progresiva de los mismos. 
Dentro de las dinámicas de la relación histórica entre sociedad y naturaleza, los recursos naturales se sitúan en el contexto social particular y constituyen parte de los procesos de transformación de la naturaleza. Por ende, los procesos de transformación de la naturaleza son comprendidos como parte de una formación socioespacial, donde participan las relaciones de producción, de poder y de decisión en variadas dimensiones, que van desde lo local a lo global. Los modos de apropiación, dominio y producción del espacio y de los recursos naturales dan cuenta de las formas de modificación del territorio y las condiciones de vida de la sociedad (Vallejos, Botana y Polh, 2009).

En la escala local es donde puede observarse más claramente el efecto acumulativo de los impactos sobre el ambiente, ya que la sola concentración de la población lleva a ejercer una mayor presión sobre los recursos y servicios ambientales; pero, asimismo, es a este nivel donde se pueden generar normativas de regulación y conservación más efectivas frente a este tipo de problemáticas. Sin embargo, cabe considerar que el nivel local difícilmente puede escapar de su dependencia con respecto a los niveles superiores de organización social y política, ya sea regional o nacional, lo que hace que las normativas deban atenerse a los marcos más generales (Reboratti, 2011).

Considerando la importancia de la escala local en el abordaje de los problemas ambientales, un claro escenario de análisis se concentra en las áreas urbanas. La relación sociedad-naturaleza en estas áreas ha desencadenado una serie de conflictos ambientales que han aumentado a través de la historia, en razón del incremento en los procesos de industrialización y urbanización, el crecimiento demográfico y la migración del campo a las ciu- dades. Las áreas urbanas no son un sistema aislado ni cerrado, por el contrario, son un sistema abierto y complejo que requiere de una visión holística e interdisciplinaria (Hernández y Méndez, 2008). La introducción del componente ambiental en la ordenación y la planificación del territorio es de gran importancia en la contribución para la mejora y la solución de los problemas ambientales urbanos. Actualmente, el ordenamiento del territorio se basa en la asignación de espacios específicos para las actividades humanas, en un territorio determinado. Esto usualmente se hace desde una perspectiva fragmentada, donde se analizan estos aspectos por separado, pero rara vez se hace un esfuerzo para integrarlos y entender las dinámicas territoriales en un espacio determinado (Guhl, 2011).

\section{Metodología}

El análisis territorial de la problemática ambiental urbana en el municipio de Facatativá se realizó bajo un enfoque descriptivo y analítico, basado en el método cualitativo, y contempló las siguientes fases de desarrollo: en su parte descriptiva, la investigación se centró en la identificación de diferentes variables que permitieran comprender la relación sociedad-naturaleza y su expresión en el territorio bajo la forma de problemáticas ambientales; en la fase analítica se realizó un análisis geohistórico del territorio que se concentró principalmente en las causas que originan los problemas ambientales, buscando explicar la ocurrencia de la problemática a partir de factores de orden político, social, económico y cultural, en los diferentes ámbitos espaciales acaecidos entre 1980 y 2010. En este sentido, el análisis se centró en la explicación de las relaciones causales entre los procesos sociales (económicos, políticos, culturales) y sus efec- 
tos en el medioambiente (Rivera, 2005), desde una perspectiva geopolítica (analizando las relaciones de poder y los actores que participan en estas las interrelaciones que han incidido en la expresión de la problemática ambiental en el territorio) y ambiental (apropiación y uso de la naturaleza y sus recursos).

Para analizar la configuración territorial en el espacio urbano del municipio de Facatativá durante el periodo de estudio, se llevó a cabo la revisión de documentos académicos e institucionales, informes, estadísticas, libros y otro tipo de estudios de carácter formal realizados en el municipio.
También se consideraron los aspectos a nivel regional y nacional que han contribuido a la configuración territorial del municipio. Esta revisión se complementó con métodos de evaluación cualitativos, tales como entrevistas semiestructuradas y observación participante. Igualmente, se realizó un análisis de todos los elementos que hacen parte de la configuración territorial del área urbana del municipio de Facatativá, con el fin de identificar los problemas ambientales durante el periodo de estudio. Para esto, los factores de los componentes naturales y sociales se articularon de manera que pudiera obtenerse un análisis territorial de acuerdo con las variables que se presentan en la Tabla 1.

\section{TABLA 1. COMPONENTES PARA LA ELABORACIÓN DEL ANÁLISIS TERRITORIAL EN EL MUNICIPIO DE FACATATIVÁ}

\begin{tabular}{|c|c|c|}
\hline Dimensión & Factor & Variables \\
\hline Natural & Oferta ambiental del territorio & $\begin{array}{l}\text { Ecosistemas estratégicos } \\
\text { Oferta del suelo } \\
\text { Oferta del recurso hídrico }\end{array}$ \\
\hline \multirow{7}{*}{ Social } & Política & $\begin{array}{l}\text { Tenencia de la tierra } \\
\text { Asentamientos humanos } \\
\text { Grupos de poder }\end{array}$ \\
\hline & Sistema económico & $\begin{array}{l}\text { Actividades económicas } \\
\text { Influencia de la economía nacional y regional }\end{array}$ \\
\hline & Cultura & $\begin{array}{l}\text { Valores e ideologías } \\
\text { Imaginarios urbanos y memoria }\end{array}$ \\
\hline & Población & $\begin{array}{l}\text { Dinámica poblacional } \\
\text { Migración } \\
\text { Distribución espacial de la población }\end{array}$ \\
\hline & Vivienda & $\begin{array}{l}\text { Dinámicas en la construcción de la vivienda } \\
\text { Programas de vivienda }\end{array}$ \\
\hline & Crecimiento urbano & $\begin{array}{l}\text { Expansión urbana } \\
\text { Procesos históricos de ocupación del suelo }\end{array}$ \\
\hline & Servicios públicos & $\begin{array}{l}\text { Servicio de agua y alcantarillado } \\
\text { Limpieza y saneamiento } \\
\text { Gestión de residuos sólidos }\end{array}$ \\
\hline
\end{tabular}




\section{Desarrollo y discusión}

A continuación se presenta el análisis de los principales factores sociales, económicos y culturales que contribuyeron en la problemática ambiental del municipio de Facatativá entre 1980 y 2010, teniendo en cuenta las dinámicas locales, regionales y nacionales ejercidas sobre el territorio y que le han brindado una identidad a sus paisajes. Este análisis, realizado bajo una perspectiva analítica y crítica, tiene el propósito de convertirse en la base principal para la formulación de estrategias de implementación y gestión ambiental territorial, considerando las intensas relaciones regionales en las que se encuentra inserto el Distrito Capital y los demás municipios de la sabana de Bogotá.

\subsection{Crecimiento demográfico y su impacto en el territorio}

Facatativá ha sido considerada desde inicios del siglo XX como una ciudad en crecimiento. Fue capital del departamento de Cundinamarca, la capital ferroviaria y la ciudad más comercial, factores que actuaron directamente en su crecimiento demográfico. Desde entonces y hasta la década del sesenta, el crecimiento demográfico del municipio mostró un incremento moderado y constante en el tiempo, consolidándose así como uno de los municipios con más habitantes de la región, ya que superó a otros de su área de influencia, como Madrid, Funza y Mosquera, que también estaban siendo impactados fuertemente por la misma dinámica de crecimiento poblacional.

Desde la década de los ochenta, el comportamiento demográfico en el municipio mostró un crecimiento acelerado, especialmente en el área urbana, donde comenzó a establecerse gran parte de la población migrante de otras regiones del país y de Bogotá, gracias a la expansión de los cultivos de flores en el municipio, su cercanía con Bogotá y la infraestructura de servicios bancarios, de comunicación y transporte. Después de Soacha, $\mathrm{Fa}$ catativá ha sido el segundo municipio receptor de población migrante en la sabana de Bogotá (Tabla 2) (Preciado, 2015).

TABLA 2. EVOLUCIÓN DE LA JERARQUÍA POBLACIONAL URBANA EN LA SABANA DE BOGOTÁ ENTRE 1993 Y 2005

\begin{tabular}{|c|c|c|c|c|c|}
\hline \multicolumn{2}{|c|}{1985} & \multicolumn{2}{|c|}{1993} & \multicolumn{2}{|c|}{2005} \\
\hline Municipio & Población & Municipio & Población & Municipio & Población \\
\hline 1. Bogotá & 4.227 .706 & 1. Bogotá & 4.945 .448 & 1. Bogotá & 6.778 .691 \\
\hline 2. Soacha & 103.700 & 2. Soacha & 230.335 & 2. Soacha & 398.295 \\
\hline 3. Zipaquirá & 47.376 & 3. Zipaquirá & 69.695 & 3. Facatativá & 106.067 \\
\hline 4. Facatativá & 46.060 & 4. Facatativá & 69.552 & 4. Zipaquirá & 100.038 \\
\hline 5. Funza & 25.291 & 5. Chía & 45.696 & 5. Chía & 97.444 \\
\hline
\end{tabular}

Fuente: Elaboración propia a partir de datos del Departamento Administrativo Nacional de Estadística (DANE, 1985, 1993 y 2005) 
En el periodo intercensal 1985-1993, Facatativá mostró una tasa de crecimiento promedio anual del $4,6 \%$ en su área urbana, mientras que en el área rural se observó una disminución de la población, una tendencia generalizada a nivel nacional y en la sabana de Bogotá. El incremento poblacional en el área urbana del municipio empezó a generar algunos conflictos sociales propios del proceso de territorialización debido a que se comenzó a desbordar la capacidad de carga $^{3}$ del municipio en aspectos como la prestación de servicios públicos, tales como el agua y los servicios de salud y educación.

3 La capacidad de carga hace referencia a la resistencia que un determinado sistema natural o construido soporta antes de sufrir variaciones sustanciales que alteren sus características fundamentales, o que lo puedan llevar a un colapso (López Trigal, 2015). Por ende, hace referencia a las alteraciones ambientales y sociales del municipio como consecuencia del crecimiento poblacional acelerado que lleva a la afectación en la prestación de servicios básicos, necesarios para el bienestar de la población.
Durante la década de los noventa se observó un incremento moderado de la población, con tasas de crecimiento hasta de $3,4 \%$ en la primera mitad de esta década. Desde la segunda mitad de los años noventa, la tasa de crecimiento comenzó a mostrar un comportamiento estable, con una tendencia a la disminución hasta la primera década del 2000, cuando llegó a una tasa de crecimiento de $2,5 \%$. De acuerdo a las proyecciones realizadas por el DANE (2005), al finalizar la primera década del siglo XXI la tasa de crecimiento poblacional en el municipio de Facatativá disminuiría hasta un $2 \%$; sin embargo, a pesar de que el crecimiento se mantuvo constante, se observa que siguió aumentando hasta alcanzar los 119.849 habitantes en el año 2010 (Figura 2).



1993199419951996199719981999200020012002200320042005

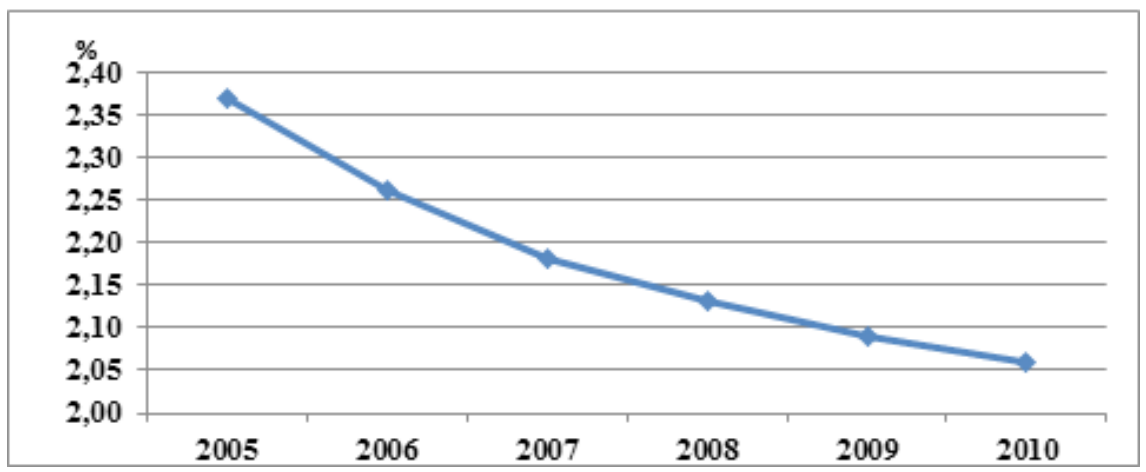

FIGURA 2.

Facatativá: tasas de crecimiento poblacional anual 1993-2005 (arriba); proyección de las tasas de crecimiento poblacional 2005-2010 (abajo)

Fuente: Elaboración propia a partir del DANE (2009, 2005). 
En definitiva, estas dinámicas del crecimiento poblacional en el municipio han intervenido en la intensificación de la problemática ambiental que se viene presentando desde hace muchos años y se incrementó en el periodo de estudio. Factores de índole social (económico, cultural y político) que se han manifestado a diferentes escalas (nacional y regional), así como el desplazamiento forzado de la población, la crisis del sector agrario, la industrialización y la liberalización económica, han generado una tendencia de ocupación del territorio rural y de suelos con valores de conservación en el municipio; y más crítico aún es el desarrollo de la periferia, con asentamientos en zonas de alto riesgo geológico y ambiental que se constituyen en una fuerte amenaza para las familias que construyen allí sus viviendas, como es el caso de los barrios Las Palmas y Las Lomas en el sector de Cartagenita, por citar algunos ejemplos. Estos aspectos también han influido en una alta demanda de bienes y servicios, necesarios para asegurar la calidad de vida de la población. El municipio, históricamente, no ha tenido una infraestructura de servicios públicos que garantice el abastecimiento del total de los habitantes en el territorio, lo que genera un grave problema para la población y una presión sobre recursos naturales como el agua y otros servicios ambientales.

\subsection{Crecimiento urbano y vivienda: promotores de la vulnerabilidad ambiental y social en el territorio}

El municipio de Facatativá ha tenido una fuerte influencia de las dinámicas de territorialización que se presentaron históricamente en la sabana durante el siglo XX. El área urbana del municipio creció durante todo este siglo y en la primera década del 2000. A inicios del siglo XX el municipio estaba conformado por 30 manzanas que se desarrollaron en un modelo de ciudad compacta, donde la plaza principal se definió como eje social alrededor del cual se desarrollaban las actividades funcionales de la ciudad que influyeron en la aparición de algunas dinámicas de carácter disperso y propiciaron una nueva estructura territorial con la construcción de nuevas vías de comunicación (Solano, 2011).

Desde los años cuarenta hasta finales de la década de los setenta del siglo anterior, los acontecimientos políticos y económicos que dieron lugar a los desplazamientos masivos de población campesina y rural intervinieron en el incremento poblacional del municipio, dando origen a la aparición de los primeros asentamientos informales en la periferia norte de la ciudad (Solano, 2011). En el municipio ya existían vías de comunicación con Bogotá y el Ferrocarril de la Sabana, que establecía conexión entre Bogotá y Facatativá y era punto clave para la comunicación con Girardot. Sin duda, el desarrollo de la actividad ferroviaria en el municipio se convirtió en uno de los detonantes del crecimiento urbano en esta época.

En la década de los sesenta, la urbanización tuvo un ritmo de crecimiento lento por la deficiencia en la prestación de servicios de saneamiento básico. No obstante, se construyeron las primeras grandes fábricas en el municipio, entre estas, Yanbal, en la zona noroccidental, la refinadora de maíz Promasa (ahora Alimentos Polar) y Almaviva, ubicados en la en la parte suroriental. En este mismo sector también se dio apertura a la cantera La Recebera para la explotación de roca arenisca. Estas actividades actuaron como polos de desarrollo urbano e impulsaron la ilegalidad de la propiedad y el uso de la tierra y la informalidad de sus construcciones; esto se suma a la actividad expansiva de la 
agroindustria de las flores, que atrajo un considerable flujo poblacional al municipio.

A partir de las décadas de los ochenta y los noventa comenzó el fenómeno de urbanización en serie en el municipio y se dio una consolidación hacia los bordes y los vacíos urbanos con el desarrollo de urbanizaciones en serie, con diseños uniformes, ubicadas de forma dispersa y aislada del centro de la ciudad, lo que conllevó dificultades para el acceso por falta de infraestructura vial (Figura 3).



FIGURA 3.

Número de viviendas

en Facatativá durante

los tres últimos periodos censales

Fuente: Elaboración propia a partir del DANE (1985, 1993 y 2005)
También se evidenció un acelerado proceso de urbanización de los vacíos urbanos del municipio que dio lugar a nuevos barrios en el sector central, así como la consolidación de nuevas áreas periféricas de origen informal, que llegaron incluso a urbanizar las faldas del cerro Manablanca (zona de protección ambiental de importancia ecológica para el municipio) con viviendas que, además de no cumplir con las normas urbanísticas, fueron construidas bajo un alto riesgo para la población (Figura 4). Los inquilinatos se incrementaron en el municipio y también se intensificó la división de las grandes haciendas en pequeñas propiedades, con lo cual aumentó la densidad de la población y se favoreció el cambio de uso del suelo de rural a urbano.

El fenómeno de urbanización en el municipio estuvo detenido durante un periodo de cinco años, desde 1997, a causa de la restricción que se impuso a la expedición de licencias de construcción hasta la aprobación del Plan de Ordenamiento Territorial (POT). Una vez aprobado, según el Acuerdo 69 de 2002, se reactivó la urbanización teniendo en cuenta las áreas de expansión decretadas y las prioridades por áreas funcionales en el municipio (Rincón, 2012). 


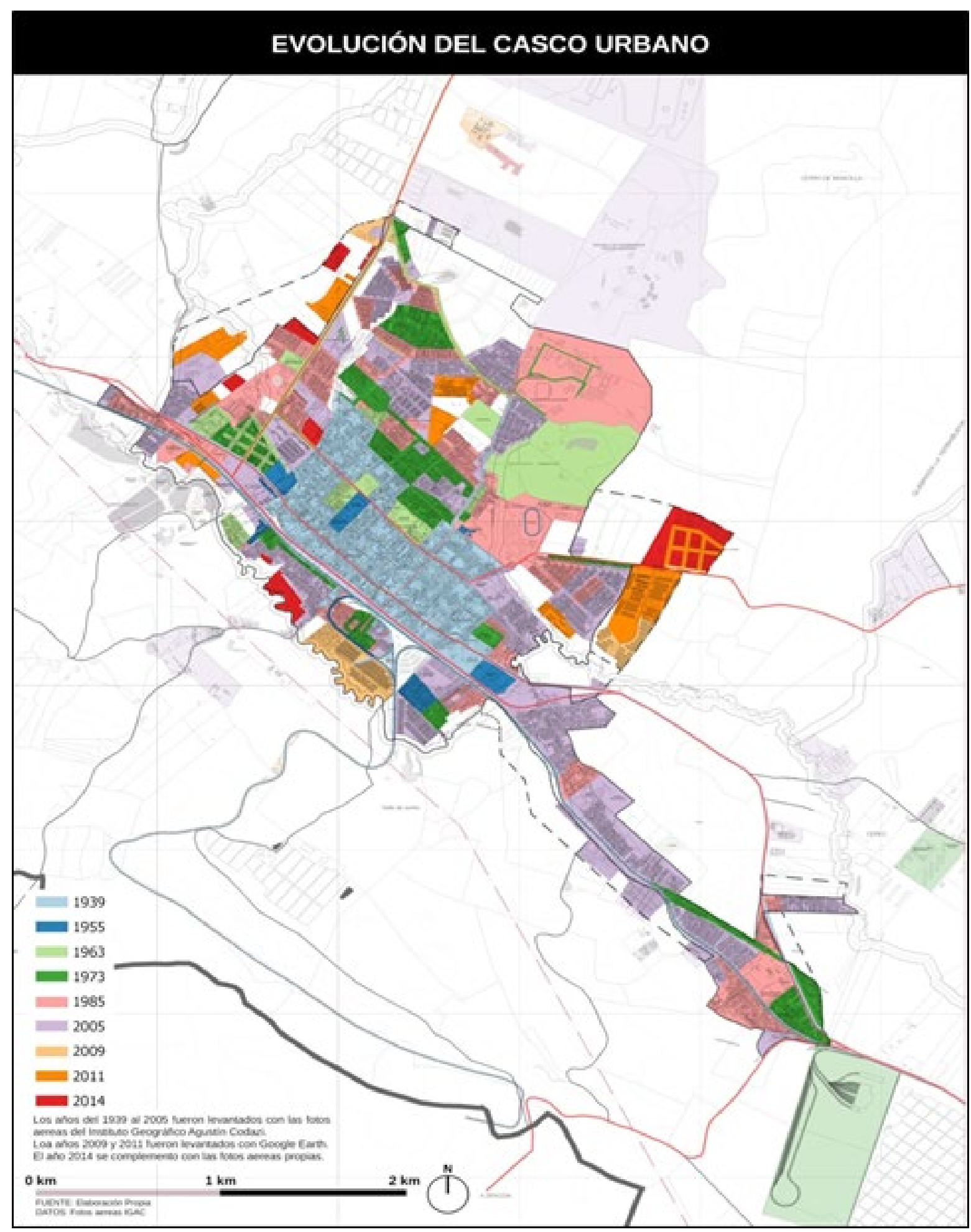

FIGURA 4.

Evolución histórica del crecimiento urbano en el municipio de Facatativá Fuente: Hábitat Integral y Alcaldía de Facatativá (2014). 
En definitiva, la territorialización expresada en la urbanización y la vivienda urbana permite comprender algunos impactos ambientales que han determinado la configuración espacial actual del municipio. En primer lugar, el área urbana ha venido creciendo a un ritmo acelerado, donde es evidente que han sido las fuerzas del poder económico y los acontecimientos de orden social y político, a nivel nacional y regional, los que han determinado este proceso, lo cual ha generado no solo el crecimiento desbordado y desordenado del territorio, sino conflictos en el uso del suelo. En consecuencia, el suelo rural se convirtió en suelo urbano por la alta demanda de vivienda, que se conseguía a precios relativamente cómodos en estos terrenos.

A lo anterior se suma el desconocimiento y la falta de sensibilidad hacia los recursos naturales y los ecosistemas que hacen parte de la Estructura Ecológica Principal ${ }^{4}$ del municipio. Un claro ejemplo de esto es el río Botello, principal fuente de agua superficial del municipio en el que muchos barrios, por falta de un sistema de alcantarillado, depositan sus aguas negras directamente, así como la invasión de zonas de interés ambiental, como el cerro Manablanca, con viviendas de origen ilegal que crean un grave problema de orden socioambiental.

4 La Estructura Ecológica Principal ha sido definida por el Acuerdo 069 de 2002 que adopta el Plan de Ordenamiento Territorial (POT) del municipio de Facatativá como la porción de territorio seleccionada y delimitada para su protección y apropiación sostenible, ya que posee elementos tanto naturales como construidos de carácter principal, que determinan la oferta ambiental del territorio y conforman un elemento estructurante a partir del cual se organiza el espacio urbano y rural

\subsection{El crecimiento económico y su influencia en la configuración socioambiental del territorio}

Facatativá, durante el siglo XX, se caracterizó por ser uno de los municipios económicamente más activos de la Sabana Occidente y actuó como centro de relevo y acceso a diferentes servicios, tanto para la población local como para los habitantes de los municipios circundantes de la vertiente alta y media de la cuenca del río Magdalena.

Aunque históricamente la economía del municipio se ha caracterizado por un fuerte desarrollo del sector primario (agricultura, especialmente de productos hortícolas) y terciario (comercio de bienes y servicios), desde las décadas de los setenta y los ochenta comenzó a desarrollar otro tipo de actividades económicas, como la floricultura y la industria. Históricamente, la actividad industrial no se había desarrollado en un área específica dentro del municipio y comenzó a establecerse de manera dispersa dentro del área urbana.

El desarrollo de la industria favoreció la consolidación de asentamientos y barrios en zonas periféricas del municipio, motivados por actores con poder económico que hicieron prevalecer sus intereses particulares y establecieron diferentes industrias en zonas alejadas del casco urbano que contaron con el consentimiento de la administración municipal. Como consecuencia, se propició un crecimiento desordenado con alto impacto en lo ambiental y en la calidad de vida de las familias allí asentadas.

Desde la década de los ochenta se inició la consolidación de establecimientos industriales, tanto en el municipio como en la sabana. A pesar de la fuerte influencia de las deseconomías de aglome- 

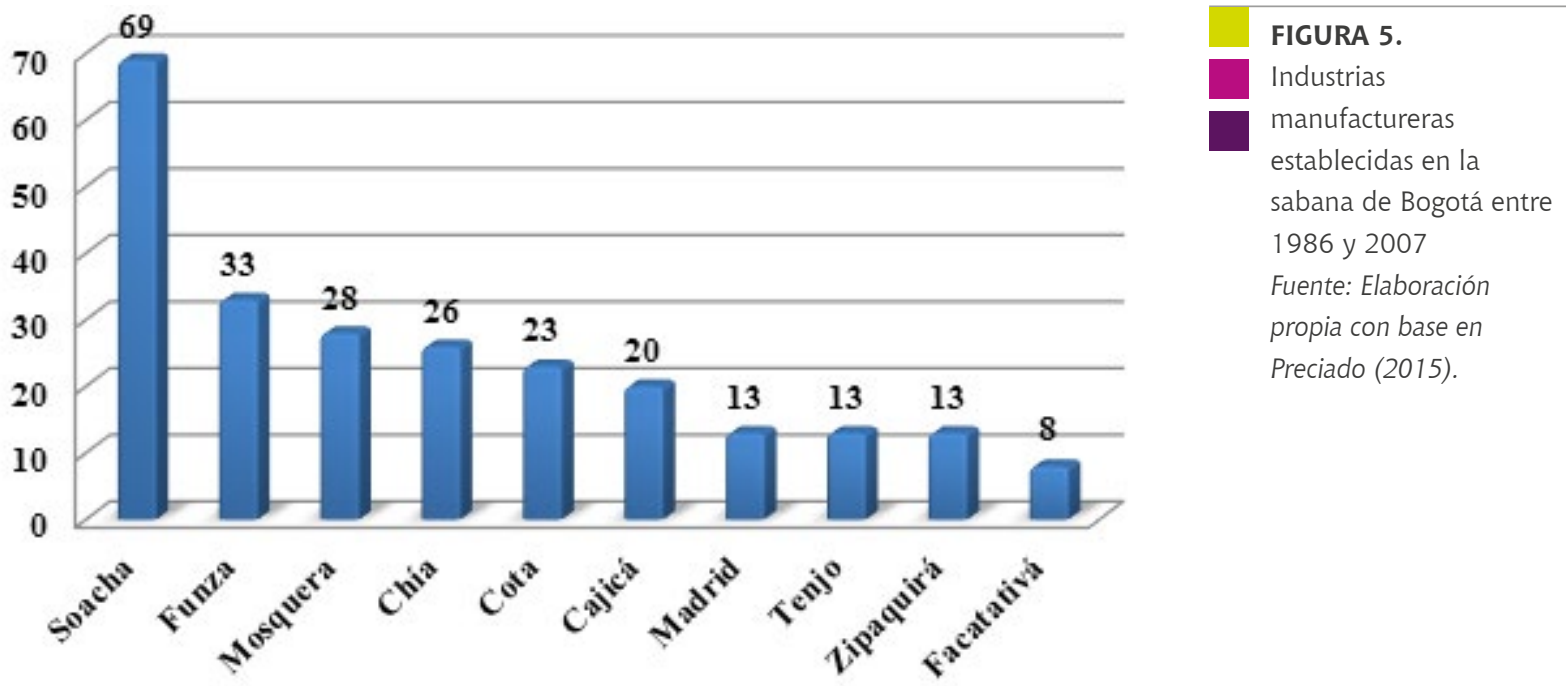

ración y la descentralización industrial en Bogotá, que impulsaron el establecimiento industrial en diferentes municipios sabaneros (para las últimas tres décadas, en el caso de la industria manufacturera), el número de industrias que se establecieron en el municipio de Facatativá fue relativamente menor comparado con otros municipios sabaneros (Figura 5).

De acuerdo con el Informe del estado de los recursos naturales de la Contraloría Municipal de Facatativá (1995), en la década de los noventa las grandes empresas son las que tienen un mayor impacto sobre el medioambiente municipal, especialmente en la calidad del aire y el recurso hídrico. Sin embargo, es importante señalar que estas industrias han demostrado que han realizado esfuerzos para optimizar sus procesos de producción y las tecnologías que utilizan para reducir su impacto ambiental, así como del desarrollo de políticas y planes de manejo ambiental.

Para el año 2009, ya se habían establecido en el municipio otras industrias dedicadas a la distri- bución de gas y una zona franca de biocombustibles. Como consecuencia, el establecimiento de empresas multinacionales no solo en el municipio, sino en la sabana, se ha venido incrementando, lo que ha intervenido en la transformación del paisaje junto con el acelerado crecimiento de la vivienda.

También es importante mencionar la floricultura debido al impacto ambiental y social que ha generado, aunque no se realiza en el área urbana del municipio. Históricamente la floricultura no ha sido la actividad económica predominante en el municipio, comparado con Madrid, Funza y Mosquera. No obstante, a principios de la década de los ochenta Facatativá mostró un alto crecimiento de los cultivos de flores y se llegaron a establecer 32 cultivos, con un total de área sembrada 188,6 ha para inicios de la década de los noventa. Para el año 2000 el área destinada a esta actividad alcanzó una extensión cultivada de 290,36 ha en el municipio (Figura 6) (Gobernación de Cundinamarca, 2010, 1999 y 1993). 


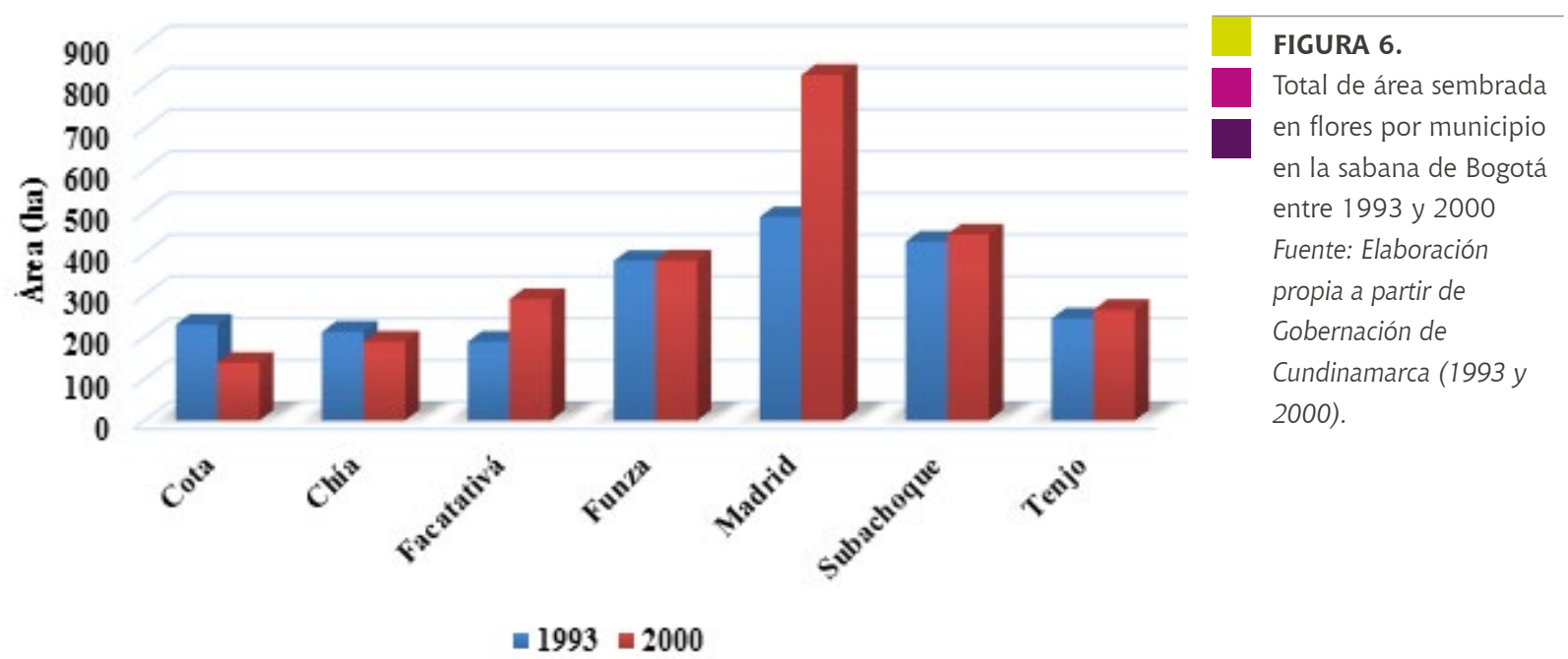

La floricultura en el municipio de Facatativá ha producido nuevas configuraciones espaciales y de apropiación del territorio y ha generado un alto impacto ambiental no solo por la demanda de grandes cantidades de agua requeridas para el cultivo (aproximadamente $10.300 \mathrm{~m}^{3}$ por ha), sino por la contaminación que se produce por el uso de pesticidas y fertilizantes con altos niveles de toxicidad, que pueden llegar a causar graves problemas de salud en las personas que los manipulan (Montañez, 1992).

Es innegable que el gran impacto ambiental que esta actividad genera en el medioambiente se refleja en el recurso hídrico y el suelo. La contaminación hídrica se produce cuando el agua que se utiliza en el riego de los cultivos, por escorrentía, llega al suelo e impacta las reservas de agua subterránea o las fuentes de agua superficial. Este es un grave problema en el municipio porque gran parte del acueducto municipal depende de pozos subterráneos y de las aguas del río Botello, lo que afecta la disponibilidad de agua potable para la población. De acuerdo a con la Empresa de Acueducto y Alcantarillado de Facatativá (EAAF-ESP, 2004), se determinó la presencia de 16 tipos de pesticidas en las aguas del embalse Gatillo, una de las principales reservas de agua para el abastecimiento del municipio. Cabe aclarar que estas trazas de pesticidas no provienen solamente de los cultivos de flores, sino también de otros cultivos como papa, fresa y arveja.

Por otra parte, la actividad floricultora ha impactado en la configuración territorial y en la calidad de vida, social, cultural y formativa de los hogares que se han dedicado a esta labor, pues son las mujeres las que representan la gran mayoría de la mano de obra en la floricultura, por lo cual abandonan durante largas horas a sus hijos y desestabilizan las relaciones hogareñas, lo que produce grandes efectos en las familias y la sociedad en general: abandono y violencia. Igualmente, esta actividad, a lo largo de la historia, ha generado voluminosos desplazamientos poblacionales diarios de carácter intrarregional desde otros municipios de la sabana hasta los correspondientes lugares donde se ubican los cultivos de flores (Montañez, 1992).

Otra actividad que ha generado problemas ambientales en Facatativá ha sido la minería. A pesar de que esta actividad ha sido poco representativa en la economía municipal, estuvieron activas tres can- 
teras localizadas en el cerro Manablanca y en el barrio Cartagenita, en el sector conocido como La Recebera, de las cuales se extrajo una gran cantidad de material para construcción. El impacto generado por esta actividad ha traído graves consecuencias en la salud de los habitantes del municipio: según la Contraloría Municipal de Facatativá (1995), una de las diez primeras causas de morbilidad en la población está en estrecha relación con el estado deteriorado del medioambiente, entre ellas, las enfermedades respiratorias, que para 1995 afectaba al $18,5 \%$ de la población.

Igualmente, esta actividad condujo a la transformación dramática del paisaje, que demuestra el gran deterioro del suelo actualmente erosionado y deforestado. Hasta el momento, en esta área no se ha realizado ningún tratamiento de reconstrucción morfológica ni actividades de reforestación, a pesar de que la actividad de explotación fue detenida aproximadamente hace diez años (Figura 7).

Adicionalmente, esta zona ha sido sometida a una fuerte presión por urbanización en terrenos que presentan alto riesgo geológico por procesos de inestabilidad, caída de rocas y bloques. El alto nivel de desprotección vegetal en la zona la ha tornado en un área vulnerable a deslizamientos por la poca o nula infiltración del agua en el suelo desprotegido, afectando así el ciclo hidrológico tanto para las aguas superficiales como las subterráneas.
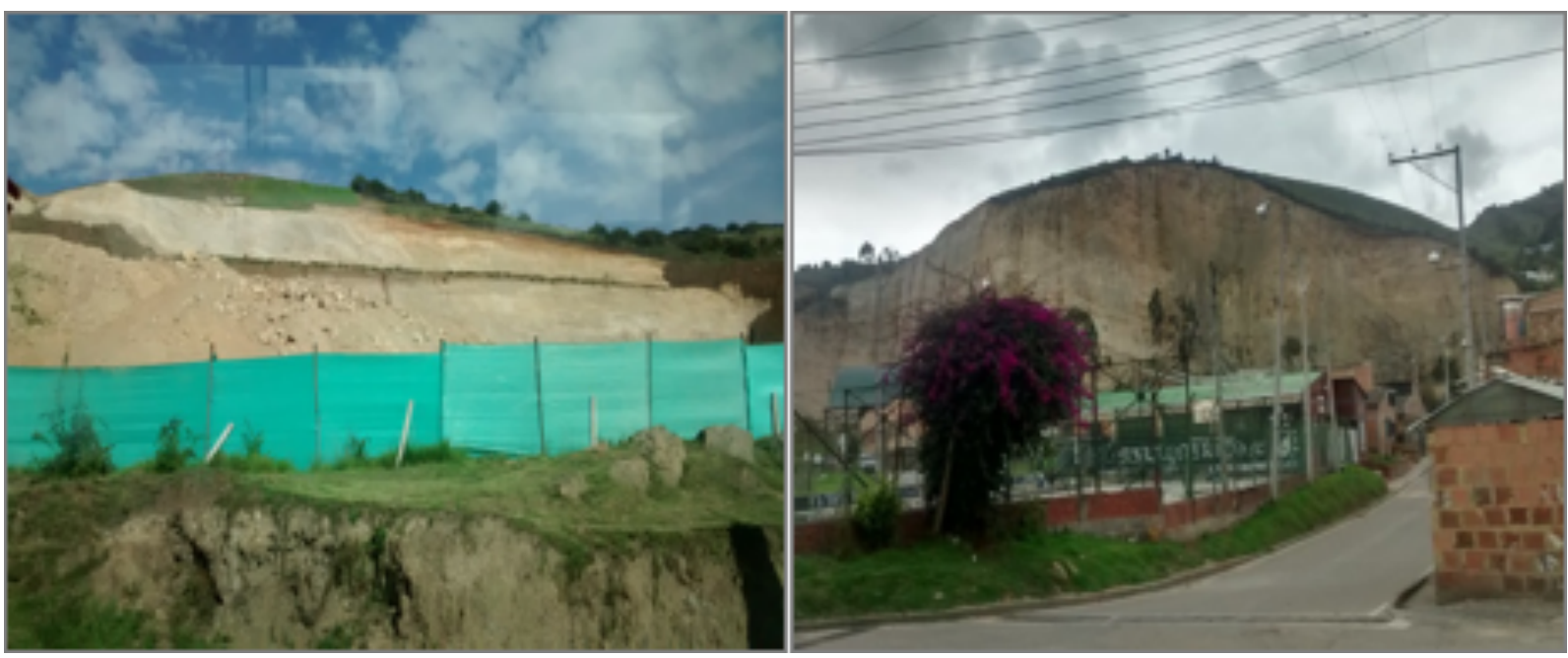

FIGURA 7.

Cantera en el sector Manablanca (izquierda); cantera en el sector La Recebera, en el barrio Cartagenita (derecha)

Fuente: Elaboración propia.

\subsection{El estado de los servicios públicos en Facatativá}

El municipio de Facatativá, a lo largo de su historia, ha presentado problemas en la infraestructura de sus servicios públicos. El acueducto es el principal, por la falta de un sistema de calidad capaz de cubrir las necesidades de sus habitantes, pues durante todo el siglo XX y hasta la década de los sesenta el municipio contaba con un sistema de 
acueducto arcaico que tuvo que enfrentar dificultades a nivel técnico y financiero como consecuencia de incumplimientos de los contratos, dificultades de orden técnico y la voluntad de los gobernantes de turno.

Para la década de los setenta, con el objetivo de solventar el problema, se construyó el embalse El Gatillo, se instaló una planta purificadora de agua, se construyeron tanques de captación y distribución, se cambió parte de la tubería urbana y se perforaron tres pozos subterráneos para abastecer la demanda de agua, condiciones que, además de garantizar el suministro de agua potable para gran parte de la población, dio solución al problema del acueducto que afectó al territorio por más de cien años (Olivos, 2011).

No obstante, para la década de los ochenta el problema del acueducto continuó presentándose en el municipio, no en el sistema de abastecimiento como tal, sino en torno al déficit en la capacidad del suministro de agua potable disponible para cubrir la alta demanda del servicio. Frente a estas deficiencias, se puso en marcha la construcción de dos embalses más y de un nuevo tanque de distribución con sus respectivas redes.

Las fuentes de abastecimiento que han alimentado el acueducto del municipio han sido aguas superficiales y subterráneas que proporcionan una ventaja frente a otros municipios de la sabana de Bogotá, que no cuentan con un sistema de acueducto propio y deben comprar agua en bloque a Bogotá. La principal fuente que abastece al acueducto municipal es el río Botello y sus afluentes, las quebradas La Pava y Mancilla y algunas fuentes de agua subterránea. No obstante, la oferta de agua subterránea en el municipio es preocupante debido a que ha venido disminuyendo significativamente por su alto grado de extracción y porque la gran mayoría de los embalses tienen una vida útil hasta el año 2020. Esta situación es alarmante, ya que el municipio deberá suplir su demanda con otras fuentes complementarias que aún no han sido planificadas.

De otra parte, en la década de los noventa, la Contraloría Municipal identificó como uno de los grandes problemas ambientales del municipio el deficiente manejo de los residuos sólidos por parte de la comunidad, el comercio, las industrias y la agroindustria de las flores, tanto en el área urbana como en la rural. En varios sectores del área urbana se ha observado acumulación de basuras y de escombros, dispuestos en lugares inadecuados y en los días en que no se hace recolección; incluso la disposición de residuos sólidos se hace directamente en las fuentes de agua del municipio, lo cual ocasiona un gran foco de infección e insalubridad para la población. Se estima que en la década de los ochenta la cantidad de residuos sólidos generados por el área urbana del municipio oscilaba entre 900 y 1.200 toneladas mensuales (Contraloría Municipal Facatativá, 1995). Entre las décadas de los noventa y del 2000, el promedio de residuos generados en el municipio fue de 33.082 toneladas al año, lo que equivale a 1.923 toneladas mensuales (Gobernación de Cundinamarca, 1999, 2010).

Adicionalmente, el problema más grave que tiene el municipio es la disposición final de sus residuos sólidos, ya que estos han sido trasladados y depositados en el relleno sanitario Mondoñedo, el cual, además de recibir los vertimientos del municipio de Facatativá, recibía los residuos sólidos provenientes de 43 municipios de Cundinamarca. Desde finales del año 2005, el relleno sanitario Mondoñedo cerró sus operaciones, por lo que a partir de ese momento la disposición de residuos se realiza en 
el relleno sanitario Nuevo Mondoñedo, ubicado en el municipio de Bojacá (Instituto Biodiversidad, 2005). Esta situación es preocupante, ya que el municipio ha venido generando un problema ambiental de carácter regional al depositar y trasladar sus desechos a otro municipio donde se localiza el relleno sanitario, lo cual crea graves impactos ambientales en el aire, el suelo y las fuentes subterráneas por la generación de gases y lixiviados.

\subsection{Estado del recurso hídrico en el municipio de Facatativá}

El municipio hace parte de la cuenca del río Bogotá en el área de influencia de las subcuencas del río Bojacá y el río Subachoque, en la cuenca del río Balsillas. El río Botello, la principal fuente hídrica del municipio, nace en el cerro Peñas del Aserradero, en la vereda La Tribuna, a una altura de 3.000 m s. n. m. Su recorrido es de aproximadamente $20 \mathrm{~km}$ e irriga las veredas La Tribuna, La Selva, Los Manzanos y Pueblo Viejo del municipio de Facatativá. La subcuenca del río Botello tiene una extensión de 10.893 ha, localizadas en su totalidad en el territorio municipal, el cual tiene como afluentes a las quebradas La Pava, La Laja y Mancilla, así como algunos drenajes directos que aportan caudal adicional al río y conforman las fuentes de agua del acueducto municipal (Figura 8).

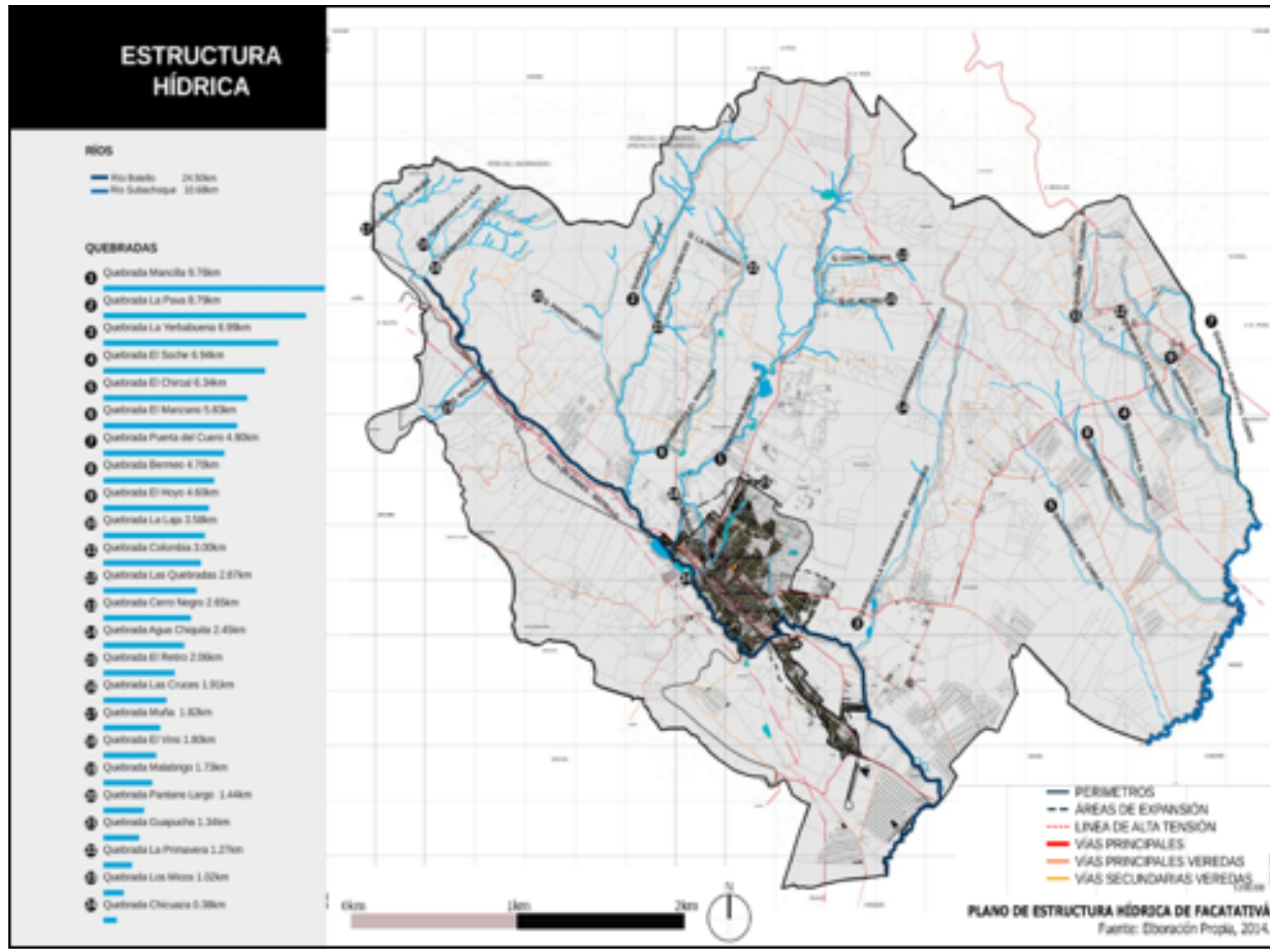

FIGURA 8.

Estructura hídrica del municipio de Facatativá

Fuente: Hábitat Integral y Alcaldía de Facatativá (2014). 
A pesar de que el territorio municipal es rico en fuentes de agua y presenta una alta recarga de acuíferos, estos se han visto drásticamente afectados desde décadas atrás por cambios en la cobertura vegetal, donde la deforestación y la introducción de especies exóticas que demandan altas cantidades de agua en sus procesos ecofisiológicos alcanzó el $60 \%$ en los cuerpos de agua municipales. Por otra parte, los altos niveles de urbanización y la ocupación espacial de los valles aluviales de los ríos y quebradas del área urbana han causado un efecto directo sobre el uso y el manejo de las aguas superficiales en términos de calidad y cantidad.

Igualmente, se han encontrado descargas puntuales de materia orgánica provenientes de granjas avícolas y porcinas ubicadas en las zonas de ronda de las fuentes hídricas, y descargas de aguas negras de algunas partes del área rural y urbana directamente sobre los cuerpos de agua superficial, principalmente en el río Botello.

Lo más preocupante de esta problemática es el bajo control que existe por parte de las autoridades ambientales respecto al detrimento de la calidad del recurso y del medioambiente en general. Durante el periodo de estudio, se encontró que las autoridades locales reconocen la problemática y de hecho han propuesto planes para la conservación de las cuencas enfocados hacia la restauración de las riberas de los ríos y quebradas y hacia el rastreo de captaciones ilegales. Sin embargo, el seguimiento y el control en la ejecución de estas actividades han sido mínimos, por lo que estos aspectos continúan siendo un problema.

Por su parte, la situación de los humedales en el municipio es preocupante, pues se encuentran en estado de deterioro, degradación permanente e indiferencia por parte de las autoridades locales y la comunidad, al punto en que algunos están al borde de desaparecer (Tabla 2). Entre los más críticos del área urbana está el humedal Las Tinguas, que era considerado como uno de los más grandes del municipio, con un área de $6.000 \mathrm{~m}^{2}$ que en los últimos 15 años se han venido reduciendo a $5.466 \mathrm{~m}^{2}$. La contaminación por residuos sólidos y vertimientos domésticos, la invasión de su ronda hídrica y los procesos de urbanización sobre el humedal han sido sus principales agentes de degradación y destrucción. Además, la construcción de la calle 15 y del Parque Lineal y Ambiental Las Tinguas durante los años 2009 y 2010 determinó su fragmentación en dos partes.

TABLA 2. HUMEDALES DEL ÁREA URBANA DEL MUNICIPIO DE FACATATIVÁ

\begin{tabular}{ccc} 
Nombre & Área (ha) & \% \\
\hline Humedal Gatillo 1 & 1,59 & 33,8 \\
\hline Humedal Guapucha & 0,66 & 14,0 \\
\hline Humedal Las Tinguas & 0,5 & 10,6 \\
\hline Humedal Villanueva & 0,001 & 0,02 \\
\hline Humedal Gatillo 2 y 3 & 1,59 & 33,8 \\
\hline Humedal El Desecho & 0,015 & 0,31 \\
\hline Humedal Los Micos & 0,33 & 7,0 \\
\hline Humedal Piedras de Tunjo & 0,015 & 0,31 \\
\hline Total & 4,701 & $100 \%$ \\
\hline
\end{tabular}

Fuente: Corporación Autónoma Regional de Cundinamarca (CAR, 2011) 
Otro de los humedales en condiciones críticas es el de Villanueva, uno de los que más ha mostrado reducción de su superficie dentro del área urbana del municipio. El humedal contaba con un área de $200 \mathrm{~m}^{2}$, pero las nuevas urbanizaciones que fueron construidas en la zona invadiendo su área de ronda y acabaron con gran parte de este hasta reducirlo a un área de $4 \mathrm{~m}^{2}$.

La problemática de los humedales refleja el bajo e insuficiente control que ejercen las autoridades ambientales municipales en el manejo sostenible de estos ecosistemas, pues en muchos casos su preservación se basa en su delimitación con mallas o cerramientos. Esta condición, además de ser una práctica completamente inadecuada para alcanzar tal fin, hace que los ecosistemas acuáticos pierdan sus funciones ecológicas y socioculturales, y que además el municipio pierda un importante mecanismo natural de adaptación al cambio climático. Por lo tanto, el manejo para la recuperación y la conservación de estos ecosistemas debe ser integral y sostenible en el tiempo, con la participación de la ciudadanía y demás entes territoriales que tienen responsabilidad en su cuidado y protección.

\section{Conclusiones}

La problemática ambiental urbana en el municipio de Facatativá es el resultado de los diferentes procesos de territorialización que históricamente se han llevado a cabo, expresados en los procesos de urbanización e industrialización consolidados en el territorio. Precisamente estas dinámicas han sido la respuesta a varios hechos que incidieron con fuerza desde la segunda mitad del siglo XX: el proceso de metropolización de Bogotá y de la sabana, y la liberalización de la economía que ha abierto los límites a un intercambio económico, político y cultural a nivel internacional. Estos hechos han propiciado un crecimiento desordenado y caótico, que sobrepasa límites, ignora autoridades locales y absorbe municipios y territorios vitales para la sostenibilidad ambiental.

La problemática ambiental identificada tras el análisis geohistórico realizado es una clara expresión local de estos acontecimientos nacionales y regionales con la influencia de Bogotá como ciudad central, cuya expansión urbana ha venido afectando de manera diferencial a los municipios de la sabana. Bajo este contexto, a pesar de que Facatativá es un municipio con una importante riqueza de recursos naturales, su historia ha permitido comprender que estas ventajas territoriales han estimulado los procesos de transformación territorial que han creado el escenario propicio para ser sometido a fuertes relaciones de poder y de apropiación, lo cual conduce a una urbanización desordenada, a la instalación de la agroindustria de flores, a la actividad industrial y la extracción minera, prácticas que se han desarrollado muy lejos de propiciar la calidad ambiental y social del municipio y que, por el contrario, han dado mayores ventajas a la productividad y la rentabilidad de sus procesos productivos.

Indudablemente la comprensión de estas condiciones de degradación y transformación ambiental en el área urbana del municipio deben ser el punto de partida para lograr una gestión ambiental urbana, enfocada al mejoramiento continuo y la construcción colectiva del territorio, donde se concierten y ejecuten estrategias específicas de corto, mediano y largo plazo que contribuyan a la solución de la problemática ambiental urbana. Para ello, la par- 
ticipación de actores públicos y privados, de los entes territoriales, como la CAR, y de la sociedad civil, deben liderar este proceso de manera concertada y participativa, y considerar los instrumentos de política pública que rigen la normativa actual, que aplica para la consecución de este objetivo.

Los problemas ambientales del municipio, así como sus soluciones, no deben darse de una manera aislada de la realidad en la que este se encuentra inmerso, pues, como se ha afirmado, las causas que han dado origen a estas problemáticas han sido la expresión local de unas dinámicas territoriales del contexto regional y nacional, propiciadas por el neoliberalismo. Por ende, teniendo en cuenta que Facatativá se encuentra inmerso en un proceso de metropolización cuyas dinámicas económicas, sociales y políticas no están apartadas de aquellas de la ciudad central y sus territorios circunvecinos, las soluciones deben ser abordadas desde un contexto territorial y geopolítico. En consecuencia, debe considerarse al territorio en su totalidad para converger en los procesos de planificación del territorio, ya que el surgimiento de los conflictos ambientales ha sido un tema general para todo el territorio y exigen un análisis interdisciplinario e integral desde la relación sociedad-naturaleza.

De esta manera, la gestión ambiental urbana debe estar orientada al reconocimiento de la problemática ambiental urbana para que, con base en esta, se formulen estrategias encaminadas a la búsqueda de soluciones concretas y aplicables en el territorio, que incluyan el desarrollo de capacidad institucional, monitoreo, seguimiento, evaluación de las acciones y retroalimentación o medidas de manejo correctivo frente a las estrategias planteadas. Considerando lo anterior, a continuación se presentan algunos aspectos bajo los que debe estar enfocada la gestión ambiental urbana en el municipio de Facatativá:

- El desarrollo de una política de vivienda a nivel municipal que permita responder a la demanda actual y proyectada según la dinámica demográfica, para reducir la especulación inmobiliaria.

- Planificar la ejecución de proyectos encaminados a asegurar la oferta de agua a largo plazo en el municipio, considerando la creciente demanda por el recurso.

- Gestionar la consecución de instrumentos económicos (por ejemplo, a través de alianzas público-privadas) que permitan la asignación de recursos financieros para el desarrollo y la puesta en marcha de los proyectos formulados para la gestión de residuos.

- Asegurar la prestación de servicios públicos domiciliarios de agua y alcantarillado en toda el área urbana, para lo cual se hace indispensable asignar recursos para la construcción y la puesta en marcha de una planta de tratamiento de aguas residuales para los sectores de Cartagenita y Manablanca, cuyo sistema de alcantarillado aún continúa depositando los vertimientos de aguas negras directamente sobre el río Botello.

- Fortalecer las estrategias de educación ambiental en temas como la apropiación del territorio, la valoración y la conservación de sus recursos naturales y sus ecosistemas estratégicos, de manera vinculante.

- Incentivar y brindar oportunidades de innovación tecnológica e investigativa en el municipio que permitan la realización de diagnósti- 
cos de línea de base sobre las problemáticas geográfico-ambientales puntuales que se están presentado, y que también reconozcan la formulación de proyectos y estrategias tendientes a solucionarlas. Esta labor puede ser impulsada por la Administración Municipal, en alianza con las universidades que se encuentran en el municipio.

Finalmente, es indispensable obtener una visión más integral del territorio, para lo cual, bajo una perspectiva geográfica, es necesaria la integración de la geohistoria, la geopolítica y la dimensión ambiental para comprender el territorio y los procesos de territorialización que se presentan bajo criterios y políticas que desbordan el ordenamiento local y niegan formas de autonomía in- dispensables para una gobernanza del territorio. Hoy, procesos como el neoliberalismo, la apertura económica y la metropolización desdibujan y reconstruyen los territorios según su arbitrariedad y sus necesidades.

\section{Agradecimientos}

A la Alcaldía de Facatativá, a través de la Secretaría de Desarrollo Agropecuario y Medio Ambiente, y la Casa de la Cultura de Facatativá, entidades que suministraron la información necesaria para el desarrollo de la investigación. Igualmente, y no menos importante, al profesor Joaquín Molano Barrero, quien realizó un acompañamiento constante e incondicional en el desarrollo de este estudio. 


\section{Referencias}

Aponte, E. (2006). La geohistoria, un enfoque para el estudio del espacio venezolano desde una perspectiva interdisciplinaria. Scripta Nova, X(218). Recuperado de http://www.ub.edu/geocrit/sn/sn-218-08.htm

Contraloría Municipal Facatativá. (1995). Informe del estado de los recursos naturales, municipio de Facatativá 1995. Facatativá: Contraloría Municipal.

Corporación Autónoma Regional de Cundinamarca (CAR). (2011). Humedales del territorio CAR. Recuperado de: https://www.car.gov.co/index. php?idcategoria $=26618 \&$ download $=\mathrm{Y}$

Departamento Administrativo Nacional de Estadística (DANE). (2009). Proyecciones nacionales y departamentales de población 2005-2020. Recuperado de: https://www.dane.gov.co/files/investigaciones/poblacion/ proyepobla06_20/7Proyecciones_poblacion.pdf

Departamento Administrativo Nacional de Estadística (DANE). (2005). XVII Censo nacional de población y VI de vivienda. Recuperado de: www.dane.gov.co/index. php/estadisticas-por-tema/demografia-y-poblacion/censo-general-2005-1/sistemade-consulta-censo-2005

Departamento Administrativo Nacional de Estadística (DANE). (1993). XVI Censo nacional de población y $\mathrm{V}$ de vivienda. Recuperado de: https://formularios.dane. gov.co/Anda_4_1/index.php/catalog/113

Departamento Administrativo Nacional de Estadística (DANE). (1985). XV Censo nacional de población y IV de vivienda. Recuperado de: https://formularios.dane. gov.co/Anda_4_1/index.php/catalog/115/related_materials

Empresa de Acueducto y Alcantarillado de Facatativá (EAAF-ESP). (2004). Plan estratégico ambiental y propuesta de reglamentación para garantizar la oferta de agua al municipio de Facatativá. Informe final. Documento no publicado.

Gobernación de Cundinamarca. (2010). Anuario estadístico de Cundinamarca. Bogotá: Departamento Administrativo de Planeación.

Gobernación de Cundinamarca. (1999). Anuario estadístico de Cundinamarca. Bogotá: Departamento Administrativo de Planeación.

Gobernación de Cundinamarca. (1993). Anuario estadístico de Cundinamarca. Bogotá: Departamento Administrativo de Planeación.

Guhl, A. (2011). El medio ambiente en el quehacer geográfico de Colombia. En G. Bocco, P. Urquijo, y A. Vieyra. (coords.), Geografía y ambiente en América Latina (pp. 131-149). México: Universidad Nacional Autónoma de México (UNAM), Centro de Investigaciones en Geografía Ambiental.

Hábitat Integral y Alcaldía de Facatativá (2014). Consultoría para realizar los Estudios Técnicos para la Revisión Estructural del Plan de Ordenamiento Territorial, Facatativá, Cundinamarca. Documento no publicado. 
Hernández, T. P. y Méndez, D.C. (2008). El papel de la geografía en los conflictos ambientales urbanos. En G. A. Rodríguez, B. Londoño y G. Herrera (coords.), Ciudades ambientalmente sostenibles (pp. 281-303). Bogotá: Editorial Universidad del Rosario.

Instituto Biodiversidad. (2005). Estructuración del Plan Integral de Residuos Sólidos para el municipio de Facatativá. Documento no publicado.

López Trigal, L. (2015). Diccionario de geografía aplicada y profesional: terminología de análisis, planificación y gestión del territorio. España: Universidad de León.

López Trigal, L. y Del Pozo, P. (1999). Geografía política. España: Cátedra.

Montañez, G. (1992). ¿Hacia dónde va la Sabana de Bogotá? Modernización, conflicto, ambiente y sociedad. Bogotá: Centro de Estudios Sociales (CES), Universidad Nacional de Colombia y Servicio Nacional de Aprendizaje (SENA).

Montañez, G. y Delgado, O. (1998). Espacio, territorio y región: conceptos básicos para un proyecto nacional. Cuadernos de Geografía, 7(1-2), 120-134.

Musset, A. (2009). ¿Geohistoria o geoficción? Ciudades vulnerables y justicia espacial. Medellín, Colombia: Editorial Universidad de Antioquia.

Olivos, L. A. (2011). Historia de Facatativá. Colombia: Alcaldía Municipal de Facatativá.

Preciado, J. (2015). Desarrollo regional y medio ambiente: desafíos para la construcción de la región metropolitana de Bogotá. Colección Tierra y Vida. Bogotá: Universidad Distrital Francisco José de Caldas.

Reboratti, C. (2011). Geografía y ambiente. En G. Bocco, P. Urquijo, y A. Vieyra (coords.), Geografía y ambiente en América Latina (pp. 21-44). México: Universidad Nacional Autónoma de México (UNAM), Centro de Investigaciones en Geografía Ambiental.

Rincón, A. V. (2012). Análisis de la expansión urbana del municipio de Facatativá desde las políticas del Plan de Ordenamiento Territorial en el periodo 2002-2011. (Tesis de maestría). Bogotá: UPTC e IGAC.

Rivera, J. A. (2005). Análisis geográfico de problemas ambientales urbanos, caso geocorredor río Consota, municipio de Pereira (Risaralda). Perspectiva Geográfica, 11, 253-286. Recuperado de: http://revistas.uptc.edu.co/index.php/perspectiva/ article/view/1699

Solano, R. (2011). La informalidad en la tenencia de la tierra y la producción de vivienda urbana en Facatativá, Cundinamarca 1995-2009. Perspectiva Geográfica, 16, 197-210. Recuperado de: http://revistas.uptc.edu.co/index.php/perspectiva/ article/view/1755

Vallejos, V. H., Botana, M. I. y Polh, V. (2009). Transformaciones territoriales y problemas ambientales en la zona de los Esteros del Iberá. XI Jornadas de Investigación del Centro de Investigaciones Geográficas y del Departamento de Geografía, 12 y 13 de noviembre de 2009, La Plata. Recuperado de: http://www.fuentesmemoria. fahce.unlp.edu.ar/trab_eventos/ev.826/ev.826.pdf 